\title{
PUÉRPERA VIVENCIANDO A CONSULTA DE RETORNO E AS ORIENTAÇÕES RECEBIDAS SOBRE O PUERPÉRIO
}

\author{
PREGNANT-POSTPARTUM LIVING DEEPLY THE CONSULTATION OF RETURN AND THE \\ ORIENTATION RECEIVED ON THE POSTPARTUM \\ PUERPERA QUE VIVE PROFUNDAMENT LA CONSULTA DE RETORNO Y LAS \\ ORIENTACIONES RECEBIDAS
}

\author{
Maria de Lourdes Centa* \\ Patrícia de Resende Oberhofer** \\ J orge Chammas***
}

\begin{abstract}
RESUMO: Este estudo tem como objetivo conhecer como as puérperas vivenciam a consulta de retorno e as orientações recebidas sobre puerpério em uma unidade de serviço de saúde. Trata-se de um estudo de cunho qualitativo, realizado em uma Unidade de Saúde da cidade de São J osé dos Pinhais-PR. Participaram deste trabalho 12 puérperas com idade entre 18 e 41 anos. Os dados foram obtidos através de entrevistas semiestruturadas, sendo observado o que estabelece a Resolução n ${ }^{196 / 96}$ sobre Pesquisas em Seres Humanos. Os resultados obtidos evidenciam que as puérperas: procuram tardiamente a consulta de retorno; seguem as orientações dadas pela família; percebem que seu conhecimento cultural é desconsiderado; apontam os cuidados com os pontos da sutura da episiotomia e amamentação como foco das orientações recebidas e não sentem suas necessidades atendidas. Como categoria central FALHAS NA COMUNICAÇÃO FRAGILIZANDO AS ORIENTAÇÕES. Torna-se necessário que os profissionais revejam suas ações de modo a prestar um cuidado multidimensional, contemplando no planejamento assistencial os aspectos biopsicossociais, cultural e intelectual para contribuir, efetivamente, para um puerpério saudável e para diminuir o índice de morbimortalidade puerperal.
\end{abstract}

PALAVRAS CHAVE: Puerpério; Cuidados de enfermagem

INTRODUÇÃO

O puerpério é definido como o período que sobrevem ao parto. É, empiricamente, considerado como as 6 semanas consecutivas ao parto, porém definir o seu início e o término é tão complexo quanto definir o início e o término de uma gestação (Rezende, 1995).

Para Corrêa (1998), o puerpério é o período posterior ao parto, no qual os órgãos e sistemas envolvidos, direta ou indiretamente na gravidez e no parto, sofrem processos regenerativos, para retornarem às condições pré-gestacionais.

É uma fase de intensas mudanças biopsicosociais na vida da mulher. É freqüente o desconforto no pós-parto imediato, a dificuldade para satisfazer as necessidades de sono e repouso durante esse período, a ansiedade, a insegurança e o despreparo para assistir o bebê, as expectativas em relação ao novo membro da família, o medo da cobrança familiar, os momentos depressivos ou a depressão entre outras situações e sentimentos que a mulher experimenta por ocasião do puerpério. Esses são experimentados com mais freqüência e intensidade nas primigestas e nas puérperas que não tiveram um acompanhamento adequado no pré-natal, no parto e na consulta de retorno pós-parto.

Recebido em 20/05/02 aceito em 30/08/02

\footnotetext{
* Professora Doutora em Enfermagem pela UFSC. Coordenadora do Grupo de Estudos Família, Saúde e Desenvolvimento (GEFASED) da Universidade Federal do Paraná.

** Membro do Grupo de Estudo Família Saúde e Desenvolvimento (GEFASED). Bolsista do CNPq.

*** Membro do Grupo de Estudo Família Saúde e Desenvolvimento (GEFASED). Bolsista do CNPq.
} 
Há muitos estudos sobre os períodos que antecedem o parto e o momento do parto, porém pouco se estudou, sobretudo em nosso País, a respeito do puerpério.

Segundo Rocha (1999), rituais e tabus que permeavam o puerpério constituindo-se numa rede de proteção e cooperação à mãe, foram abandonados. Esse abandono resultou numa diminuição da atenção à mulher e do apoio familiar e social justo no momento em que ela é submetida à exigências que requerem adaptações rápidas.

Desta forma, em um país como o Brasil, influenciado por inúmeras culturas, percebe-se a forte influência do conhecimento popular-empírico e das tradições culturais e religiosas sobre os aspectos gestacionais. Para Carraro (1997), o período do puerpério é envolvido por grande carga biopsicocultural que deve ser considerada para se obter um cuidado efetivo.

Segundo Oliveira et al. (1999), a assistência puerperal deve visar o atendimento de todas as dimensões, isto é, contemplando aspectos biopsico-sócio-culturais. Para se atingir essa meta tem-se de utilizar metodologia que direcione adequadamente as ações de cuidado , considerando-se a história e o estilo de vida da mulher, tipo de parto, período de pós-parto, aleitamento materno, cuidados com o bebê, relação mãe-filho-família e comunidade entre outras variáveis que interferem nesse processo.

A assistência à puérpera é tão importante quanto a assistência durante o pré-natal. 0 preparo para um puérperio saudável começa no pré-natal, devendo ser reforçado e incrementado logo após a expulsão do feto, visando $o$ adequado restabelecimento da mulher, tanto anatomofisiologicamente quanto psicossocialmente, e a identificação precoce de quaisquer alterações atinentes ao parto. Desta forma dois preceitos básicos podem ser definidos quanto a assistência puerperal: promoção de um período saudável e a prevenção de complicações.

A redução dos fatores de morbi-mortalidade no período puerperal, está intrinsecamente relacionada com a qualidade das informações recebidas em pré-natal e no período pós-parto. Torna-se papel importante nestes momentos a relação estabelecida entre os profissionais de saúde, a puérpera e sua família. Deste modo, é preciso elaborar e executar programas de educação para saúde de acordo com o repertório ou bagagem de conhecimento da população alvo, propiciando assim a mudança de atitude e comportamento.

\section{OBJ ETIVO}

Este estudo tem como objetivo conhecer como as puérperas vivenciam a consulta de retorno e as orientações recebidas sobre o puerpério em uma unidade de serviço de saúde.

\section{MÉTODO}

Trata-se de uma pesquisa qualitativa de caráter descritivo. Utilizou-se para coleta dos dados um formulário para obter informações sobre identificação das puérperas, tipo de parto, participação no programa de pré-natal, tipos de orientações recebidas sobre o puerpério no pré-natal e no puerpério, conteúdo das mesmas, quem as forneceu, dentre outros dados considerados de relevância para o desenvolvimento da pesquisa. Todas as entrevistas foram gravadas em fita cassete, de modo a preservar a fidedignidade dos dados obtidos. Estes foram agrupados, analisados e interpretados.

O estudo desenvolveu-se em uma Unidade Básica de Saúde (UBS), localizada no município de São J osé Dos Pinhais (PR), no período de janeiro a março do ano de 2001.

0 número de participantes da pesquisa totalizou 12 puérperas, entre 18 e 41 anos de idade com média de idade de 25 anos. Destas, $50 \%$ eram multíparas e $50 \%$ eram primigestas; $50 \%$ das puérperas tiveram parto normal, $41,6 \%$ cesariana e $8,4 \%$ parto fórceps.

As puérperas apresentavam características comportamentais, sociais, econômicas, psicológicas e biológicas bastante diversificadas, ponto de fundamental relevância para o desenvolvimento do estudo. 


\section{ASPECTOS ÉTICOS}

A cada puérpera foi esclarecido os objetivos do estudo e a forma como seria desenvolvido. Após foi oferecido o impresso contendo o consentimento livre e esclarecido para ser assinado caso concordasse em participar, conforme Resolução $n^{\circ} 196$ de 10 de outubro de 1996 sobre Aspectos É ticos da Pesquisa Envolvendo Seres Humanos (Brasil, 1996). Esclareceu-se, também, que a menor possibilidade de desrespeito a sua integridade, esta seria interrompida imediatamente.

A realização deste estudo foi aprovada pelo Comitê de Ética em Pesquisa em Seres Humanos do Hospital de Clínicas da Universidade Federal do Paraná. Utilizou-se o nome de pedras preciosas para não identificar as puérperas participantes do estudo.

\section{APRESENTAÇÃO E ANÁLISE DOS RESULTADOS}

De acordo com a normatização do Programa de Assistência Integral a Saúde da Mulher e da Criança (PAISMC), a consulta de retorno em puerpério deve ocorrer o mais precocemente possível, sendo adequado 0 comparecimento entre 0 70 e o $10^{\circ}$ dia após o parto, juntamente com a primeira consulta da criança, em UBS, com a finalidade de atender as necessidades do binômio mãe-filho. Essa consulta deve enfocar aspectos preventivos, educativos e terapêuticos de acordo com as necessidades apresentadas por este grupo populacional, (Brasil, 1991).

Observou-se, no entanto, que a consulta de retorno, no local deste estudo, ocorreu, predominantemente, no puerpério tardio, ou seja, entre o 11 e e o 40 으 dia pós-parto. Este fato é bastante preocupante, uma vez que é na fase do puerpério imediato que ocorrem as principais alterações anatômicas, fisiológicas e psicológicas na puérpera, sendo este o período de maior ocorrência de alterações patológicas e do alto índice de morbimortalidade materno-infantil. É, também, neste período que as mulheres sofrem a pressão das crenças e valores culturais relacionados a situação que estão vivenciando, sendo, portanto, o momento que sentem maior necessidade de apoio e orientações em relação aos cuidados que deverá ter consigo, com a criança e com a família.

A análise dos dados nos conduziu às categorias descritas a seguir: PROCURANDO TARDIAMENTE A CONSULTA; SEGUINDO A ORIENTAÇÃO DADA PELA FAMÍLIA; PERCEBENDO A DESCONSIDERAÇÃO DO CONHECIMENTO CULTURAL; IDENTIFICANDO QUEM ORIENTA E DESCREVENDO O CONTEÚDO DAS ORIENTAÇÕES.

Na categoria PROCURANDO TARDIAMENTE A CONSULTA, as puérperas, em sua maioria, não procuraram a consulta de retorno por volta do 70 ao $10^{\circ}$ dias como preconizado pelo PAISM, Brasil, 1991. As que a procuraram tardiamente o fizeram em busca de anticoncepcional, ou para a retirada de pontos. Nas suas falas fica evidente que não vieram em busca da consulta em si para reforço de orientações ou esclarecimento de dúvidas. Informaram, ainda que foram instruídas a retornarem após 20 ou 40 dias.

"Ah, ele falou pra mim aguardar os 40 dias, né, e daí retornar, né pro pós-parto". (J ade)

"Não foi difícil de vir, não teve problema, era melhor se fosse mais perto da minha casa, mas até que foi bom eu vir a pé, eu já tô boa, já faz 30 dias, né". (Rubi)

“...já tá com 20 dias e só agora que eu vim e eu vim mais pra tomar o remédio (anticoncepcional),..." (Esmeralda)

Uma delas comentou que recebeu orientação apenas para retornar para a retirada de pontos.

"Simplesmente ela falou que 8 dias depois eu tinha que vir tirar os pontos e eu vim, daí ela mandou marcar a outra consulta pra dalí 20 dias, né, quando a nenê tivesse com 30 dias que é agora". (Topázio) 
Percebe-se a falta de validação da comunicação entre profissional e cliente, se considerarmos que a orientação foi adequada. A redução dos fatores de morbi-mortalidade puerperal estão intrinsecamente relacionados à interação adequada entre a puérpera e os profissionais do serviço de saúde. Para que este vínculo seja estabelecido e mantido é necessário que a relação entre o profissional de saúde e a mulher, seja alicerçado no respeito mútuo, confiança e competência, que inclui também a validação da compreensão das mensagens emitidas nas orientações realizadas.

Na categoria, SE GUINDO A ORIE NTAÇÃO DADA PELA FAMÍLIA, observa-se que as orientações mais aceitas pelas puérperas são as transmitidas pela família, evidenciando o papel formador e transmissor da herança cultural com seus valores, mitos e ritos.

"Eu usei a casca de banana, foi minha mãe que recomendou, eu sigo mais os conselhos dela". (Água Marinha).

“Minha sogra, minha mãe mesmo, sempre falavam pra mim: agora com a cirurgia você não pode tá comendo muita comida pesada, aí eu fui nessa...eu evito bastante, também não como salada, né, a salada com bastante vinagre dá muita cólica no nenê e de fato é verdade..."(Turmalina).

"...o meu marido falou que era pra eu comer aveia que era bom e foi só depois que eu comecei que melhorou." (Onix)

"É sempre a minha irmã que me orienta, né, eu não tenho mais mãe". (J ade)

"Minha mãe fala que não é bom comer coisa ácida que nem laranja, limão, porque dá cólica no nenê". (Ametista)

Isto demostra que apesar de estarmos vivendo em uma sociedade com tecnologia avançada, as puérperas ainda seguem os conselhos da família, visando prevenir ou recuperar a sua saúde e de seu filho durante o período puerperal. Apesar da modernidade elas seguem ritos e costumes transmitidos através de gerações evidenciando a importância e influência do conhecimento empírico na saúde.

Em PERCEBENDO A DESCONSIDERAÇÃO DO CONHECIMENTO CULTURAL, observa-se que a reação dos profissionais que atenderam as puérperas na consulta de retorno levaram-nas a perceberem a falta de respeito em relação ao que the foi transmitido culturalmente pela família.

A falta de preparo do profissional em relação a interação empática com a paciente pode ser evidenciado através das seguintes falas:

“...mas hoje mesmo o médico ficou bravo comigo, ele disse que a "mãe" não pode ir nos conselhos dos mais antigos, só comer sopa, coisas leves, né..." (Turmalina)

“Eu já dei chá pra ela, numa mamadeirinha pequenininha, e ela aceitou, mas eu dei só uma vez e não vou dar mais porque a moça que pesou brigou com a gente, disse que não é pra dar nada porque só o leite materno já tem tudo" (Ametista)

“...eles disseram que não é para passar nenhum remédio, só pra tomar os medicamentos que eles me receitaram. por sinal eu passei mercúrio e agora na 1a consulta ela me deu uma bronca". (Água Marinha)

“...mandaram eu ter bastante atenção assim com o nenê, né, na hora de dá mamá, pra ele não vomitar,..." (Rubi)

Estes depoimentos evidenciaram o exercício do poder profissional, através de ordens e cobranças, sem preocupação de verificar as reais condições das puérperas e das influências que elas recebem de sua família e de sua rede de relações. Estes fatos fazem, muitas vezes, com que elas deixem de procurar os serviços de saúde e utilizem práticas impróprias para cuidar de seu filho e de si mesma. 
Em ORIENTAÇÕES ADEQUADAS, evidenciou-se que algumas puérperas apresentavam-se satisfeitas com as orientações recebidas, referindo-se ao relacionamento mantido com o profissional como galgado em respeito e compreensão, o que pode propiciar uma assistência puerperal adequada.

"Da forma que ele me explicou foi legal, que deu pra mim cuidar certinho. Eu não senti falta de nenhuma orientação". (Água Marinha)

Acreditamos que conciliando as informações transmitidas pela família, senso comum, e pelos profissionais de saúde, conhecimento científico, poderemos construir um relacionamento centrado na confiança e no respeito mútuo que propiciará maior interação entre o serviço de saúde, a puérpera e sua família.

Em IDENTIFICANDO QUEM ORIENTA, analisamos qual o profissional de saúde que orientou as puérperas em relação ao processo gravídico-puerperal e percebemos que o profissional médico foi o mais citado. 0 enfermeiro foi citado por apenas uma puérpera sem tecer comentários sobre o como foi efetuada a orientação e qual o seu conteúdo.

“...foi o médico que me orientou." (Água Marinha)

"Foi o pediatra e os outros médicos." (Rubi)

"...e foi o médico que me falou, do hospital mesmo eu não recebi orientação nenhuma, nem sobre mim, nem sobre o bebê." (Onix)

"F oi a enfermeira que me orientou no hospital." (Diamante)

Na categoria DESCREVENDO O CONTEÚDO DAS ORIENTAÇÕES percebeu-se que as principais orientações fornecidas, pelos profissionais de saúde às puérperas relacionaram-se, principalmente, ao cuidado com os pontos, medicação e com a amamentação. Evidenciou-se a carência de informações referentes aos demais cuidados em relação à mulher, a criança e a família.

"É, pra eu ter cuidado, tomar anticoncepcional, porque a minha gravidez foi de risco, tudo, né... por causa dos pontos eles me deram uma receita, usar um pó secante, lavar, essas coisas assim." (Água Marinha)

"P rá amamentar só no peito, pra não dar chá. pra não passar nenhum remédio, só pra tomar os medicamentos que eles me receitaram." (Turmalina)

"Ele só me falou que era pra amamentar e que não era pra manter relações sexuais durante 40 dias, só isso." (Onix)

"Disseram que eu não podia erguer coisa pesada senão abria os pontos, tinha que se cuidar, que não podia abrir os pontos..." (Diamante)

“...ninguém me deu nenhuma orientação, nada. Só me deram uma apostila que fala sobre o nenê, mas não me explicaram nada, só falaram pra mim não agasalhar muito o nenê, deixa assim, que o nenê sente o mesmo calor que a gente, só". (Ágata)

Em CRITICANDO AS ORIENTAÇÕES RECEBIDAS, percebemos que as puérperas quando foram indagadas se as orientações recebidas em pré-natal e puerpério supriram suas expectativas e necessidades, elas deixaram evidente que perceberam as orientações como superficiais e insuficientes, evidenciando deficiência tanto quantitativa como qualitativa no atendimento de suas reais necessidades.

"Ah, a gente que já é mãe sabe que não é brincadeira, mas eu acho que eles tinham que dá mais orientação, falar mais com a gente, porque a gente sai dali meio sem rumo e sei lá tá tudo mudado". (Turmalina)

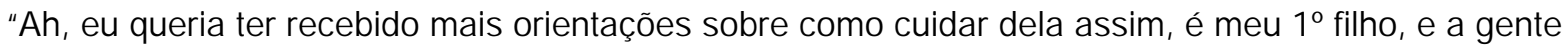
não sabe e também comigo, cuidados que eu devia ter, eu não sabia o que fazer". (C ristal) 
“... é que eu já tinha outros filhos, então eu já sabia como que era, mas se não..." (Esmeralda)

"Eu achei que o médico devia ter me orientado mais , assim mais coisa, dos cuidados, acho que eu não gostei do médico". (Ágata)

Estas falas enfocaram as necessidades sentidas pelas mulheres de receberem mais orientações, 0 que nos leva a refletir sobre a qualidade da execução das ações preconizadas pelo PAISMC/MS, no qual é incentivado a educação à saúde, como forma de promoção e manutenção da saúde.

Em FALHAS NA COMUNICAÇÃO FRAGILIZANDO AS ORIENTAÇÕES, obsera-se as falhas na comunicação entre profissionais e puérperas permeou todas as categorias já apresentadas. A análise reflexiva das categorias, através das falas que as ilustram, deixam evidente as falhas no processo comunicacional havido entre os envolvidos.

A falta de validação da compreensão das orientações talvez tenha sido uma das principais causas da procura tardia da consulta de retorno, bem como o fato das puérperas seguirem as orientações dadas pela família, culminando com a percepção de um aparente descaso pelo conhecimento cultural e a despreocupação com as reais necessidades de quem depende dos cuidados oferecidos nas Unidades Básicas de Saúde. Tornase necessário que os profissionais de saúde revejam suas ações de modo a prestar um cuidado multidimensional, contemplando no planejamento assistencial, os aspectos biopsicossociais, cultural e intelectual para contribuir efetivamente para um puérpério saudável e para diminuir o índice de morbi-mortalidade puerperal e neonatal.

0 conhecimento científico deve ser levado à população de forma decodificada, respeitando-se o repertório de cada um, clarificando seu sentido e validando sua compreensão de forma empática, humanitária, sem julgar ou reprovar o comportamento das puérperas, dando-lhes oportunidade para expressarem seu conhecimento e visualizarem possibilidades de mudança de atitude num ambiente saudável e seguro. (Stefanelli et al., 1999)

\section{CONSIDERAÇÕES FINAIS}

Embora seja preconizada a importância da consulta de retorno para detecção precoce de problemas ou agravos a saúde da mulher e da criança, evitando-se assim o aumento do índice de morbi-mortalidade materna e infantil, percebe-se que muitos profissionais da área de saúde desconsideram a importância deste momento para construir, junto às puérperas, uma concepção de saúde, de educação para saúde, de hábitos e ações saudáveis.

A consulta de retorno é fundamental para a saúde do binômio mãe-filho, pois é a ocasião que a mulher tem para esclarecer suas dúvidas e/ou aprender sobre o cuidado consigo e com o recém-nascido. É um momento singular para aprenderem com o conhecimento científico confrontando-o com o do senso comum. No entanto às puérperas, participantes deste estudo, não conseguiram sanar suas dúvidas, apresentando enorme insatisfação no que se refere as orientações sobre o puerpério.

O conhecimento empírico, transmitido através de gerações, faz parte da cultura de um povo e apresenta significado afetivo e instrutivo para os grupos populacionais, deste modo é fundamental que seja considerado como um elemento fundamental e de vital importância na implementação do plano de assistência à puérpera.

Podemos afirmar que a assistência puerperal ofertada pelo serviço de saúde, no qual realizou-se o estudo, não contemplou os aspectos biopsicosociais e culturais das puérperas. Parece-nos necessário uma reestruturação na metodologia assistencial de modo a considerar a história e o estilo de vida da mulher, tipo de parto, aleitamento materno, cuidados com o bebê, cuidados com o corpo, sexualidade, atividades físicas, relação mãe-filho-família, dentre outros.

F az-se necessário buscar a lógica que ordena tais representações a respeito do corpo da puérpera, do bebê e as relações com a família, com os profissionais e com a sociedade na qual a puérpera está inserida. Trata-se de perceber a autonomia das culturas populares no que se refere aos modos de significação e interagir com a puérpera e sua família, procurando atender suas necessidades, respeitando seus valores e cultura.

Não é suficiente informar, é preciso construir junto às puérperas e sua família uma concepção de educação para saúde. É preciso elaborar e implementar um plano de educação em saúde, fundamentado nas reais dúvidas das puérperas, considerando o meio na qual elas estão inseridas. 
ABSTRACT: This study it has as objective to know as pregmant-postpartum lives deeply the return consultation and the orientation received on postpartum in a unit of health service. This study is of the kind exploratory description taken in a Unit of Health of the city of São J ose dos Pinhais-PR. They had participated of this study 12 postpartum with age between 18 and 41 years. The data had been gotten through half-structuralized interviews. All the Aspects of Resolution $n^{\circ}$ 196/96. Lines of Direction and Regulatives Norms of the Research Involving Human beings had been observed. The gotten results evidence those pregnant-postpartum: they look the return consultation delayed; they follow the orientation given for the family; they perceive that its cultural knowledge is disrespected; they point the cares with the points of the suture of the episiotomia and breast-feeding as focus of the received orientation and they do not feel its necessities taken care of. The central category "imperfections in the communication fragility the orientation. It is necessary that the professionals review its action in order to give a multidimensional care, contemplating in the assistencial, the bio-psychological aspects, cultural and intellectual planning to contribute of efficient mode for a healthful pregnant-postpartum and to diminish the index of postpartum mortality.

\section{KEY WORDS: Puerpérium; Nursing care}

RESUMEN: Este estudio tiene como objetivo conocer como las puérperas vivenciam la consulta de retorno y las orientações recibidos durante el puerpério en una unidad de salud. Es un estudio cualitativo, llevado en una unidad de salud de la ciudad d São J osé dos P inhais-PR. Participaram de este estudio 12 puerperas com edad entre 18 y 41 datos fueram obtenidos a través de entrevistas semi-estructurados, siendo atendido qué establecem la Resolutión 196/96 sobre la investigación em Seres Humanos. Los resultados obtenidos evidenciam que las puerperas: procuran a buenas horas la consulta de retorno; siguem las orientaciones dadas a la família; perciben que su conocimento cultural és desconsiderado; senalam los cuidados com los puntos de la sutura del episiotomia y el amamantamiento és el foco de las orientaciones y ellos no sienten sus necessidades de cuidado. Como categoría substantiva "fallas de comunicacion fragilizando las orientaciones". És necesario que los profesionales repasan su acciones hacia prestar un cuidado multidimensional, comtemplando en el planificación assistencial, los aspectos bio-psico-sociales, cultural e intelectual contribuir con eficacia hacia un puerpério saludable y disminuir el índice del morbimortalidade puerperal.

PALABRAS CLAVE: Puerperio; Atención en enfermería

\section{REFERÊNCIAS}

1 BRASIL. Ministério da Saúde. Assistência institucional ao parto, ao puerpério e ao recém nascido. Brasília, 1991.

2 BRASIL. Ministério da Saúde. Conselho Nacional de Saúde. Resolução n.o 196 de 10 de out./196: Diretrizes e normas regulamentadoras de pesquisa envolvendo seres humanos. Brasília, 1997.

3 BEE, H. O ciclo vital. Porto Alegre: Artes Médicas, 1997.

4 CARRARO, T.E. A mulher no período puerperal: uma visão possível. Texto \& Contexto v.1, n.1, p. 84-91, 1997.

5 MALDONADO, M. T. Psicologia da gravidez, parto e puerpério. 14. ed. São Paulo: Saraiva, 1997.

6 MALDONADO, M.T. Psicologia da gravidez. 14. ed., São Paulo: Saraiva, 1997.

7 MONTICELLI, M. Nascimento como um rito de passagem: abordagem para o cuidado às mulheres e recém-nascidos. São Paulo, Robe, 1997.

8 OLIVEIRA, M. E. et al. Enfermagem obstétrica e neonatologica: textos fundamentais. UFSC. Florianópolis, 1999.

9 REZENDE, J. Obstetrícia fundamental. 3. ed., Rio de J aneiro: Guanabara Koogan, 1995.

10 ROCHA, F.L. Depressão puerperal: revisão e atualização. J. Bras. Psiquiatria, v. 46, n.3, p. 105-114, 1999.

11 STEFAnELLI, M. C.; CADETE, M., ARANHA, M. I. Proposta de ação educativa na prevenção da AIDS. Texto e Contexto, v.7, n.3, p. 158-173, 1998.

12 STEFANELLI, M. C.; CADETE, M. M. M.; ARANHA, M. I.; PINHEIRO, J. G.; SANTOS, A. M. Programa educativo sobre prevenção do HIV/AIDS. Rev. Gaúcha Enferm., Porto Alegre, v. 20, n. 2, p. 110-130, 1999. 